\title{
Exploratory Study on the Association between Interpersonal Violence Experiences and Alcohol Use among Adolescents
}

\author{
Neta Peleg-Oren, Gabriel A. Cardenas, Mary Comerford, and Sandro Galea
}

\begin{abstract}
Although a high prevalence of interpersonal violence among adolescents has been documented, we know very little about the association between interpersonal violence and alcohol use among adolescents. This study examines the relation between interpersonal violence experiences and alcohol use among a general random sample of 4,564 adolescents recruited through a randomized school-based survey of high school students in Florida. Overall, 30\% of high school students reported lifetime interpersonal violence through physical fights, and $8 \%$ reported being physically forced to have sexual intercourse. In multivariable multinomial weighted logistic models adjusting for gender, ethnicity, and grade, high school students who were involved in physical fights or physically forced to have sexual intercourse had greater odds of alcohol use or binge drinking in the past 30 days than students who were not exposed to these experiences. In conclusion, adolescents who have faced interpersonal violence experiences may be at a high risk for alcohol use. Findings suggest that early evaluation of interpersonal violence experiences may be important as part of alcohol use prevention programs among adolescents. The article discusses implications for social work prevention programs and recommendations for future research.
\end{abstract}

KEY WORDS: adolescents; alcohol use; binge drinking; interpersonal violence experience

A lcohol use and interpersonal violence are substantial public health problems. The 2010 Monitoring the Future survey indicated that the proportion of students involved in any consumption of alcohol in the past 30 days was $13.8 \%, 28.9 \%$, and $41.2 \%$ in grades 8,10 , and 12 , respectively. The proportion of students involved in binge drinking (five or more drinks in a row) in the past 30 days was $5 \%, 14.7 \%$, and $26.8 \%$ in grades 8,10 , and 12 , respectively. Risks related to alcohol consumption by adolescents may be immediate, such as vehicle accidents, or long term, such as development of a substance use disorder (Morris \& Wagner, 2007). Experience with alcohol use in adolescence may be particularly problematic in light of the rapid physical growth, pubertal development, and psychological and social maturation that are hallmarks of that developmental period.

Experiencing community violence, particularly interpersonal violence, is quite common among adolescents. Research has found that adolescents are at higher risk than other youth age groups for community violence experiences, with a high prevalence of such experiences (Aisenberg \& Herrenkohl, 2008; Stein, Jaycox, Kataoka, Rhodes, \& Vestal, 2003; Voisin, 2007). Data on interpersonal violence reveal that more than one-third of 10- to 16-year-olds have been victims of assault (Boney-McCoy \& Finkelhor, 1995). A study of U.S. adolescents admitted to a psychiatric inpatient unit found that $18.9 \%$ had been physically abused and $9.9 \%$ had been sexually abused during their lifetime (Evans, Spirito, Celio, Dyl, \& Hunt, 2007). Research has demonstrated that exposure to violence can be traumatic for children and is positively correlated with symptoms of posttraumatic stress disorder (PTSD) (Lynch, 2003). Although this is a vulnerable group due to the negative consequences of both interpersonal violence experience and alcohol use, there is limited literature on the co-occurrence of exposure to different traumatic experiences, interpersonal violence, and use of alcohol in population-based samples of adolescents (Langeland \& Hartgers, 1998). However, literature on adults shows substantial co-occurrence of exposure to different traumatic experiences, interpersonal violence, and use of alcohol (for example, 
Breslau, Davis, \& Schultz, 2003; Goodwin \& Stein, 2004; Hedtke et al., 2008; Kilpatrick, Acierno, Resnick, Saunders, \& Best, 1997; Spatz Widon, Raskin White, Czaja, \& Marmorstein, 2007; Vlahov et al., 2002). Evans et al. (2007) found that a history of prior psychological problems during adolescence was associated with alcohol and other illicit drug use. Most studies on PTSD among adolescents, the sentinel psychopathology associated with traumatic event exposure, have focused more on clinical populations (Deykin \& Buka, 1997; Hawke, Ford, \& Kaminer, 2005; Zatzick et al., 2006) than on general populations of adolescents and have found that the risk of PTSD among clinical populations to be much higher than in general samples of adolescents.

In the general population, studies have found that adolescents who have experienced community violence and traumatic events exhibit more psychological and behavioral symptoms than adolescents who have not experienced such events (Aisenberg \& Herrenkohl, 2008; Boney-McCoy \& Finkelhor, 1995, 1996; Margolin et al., 2009; Reijneveld, Crone, Verhulst, \& Verloove-Vanhorick, 2003; Stein et al., 2003). Despite the high prevalence of alcohol use among adolescents, we know of only four studies that have explored associations between alcohol use and violence experiences in the general population of adolescents (Giaconia et al., 2000; Hamburger, Leeb, \& Swahn, 2008; Kilpatrick et al., 2000, 2003). These studies found that exposure to various types of interpersonal violence experiences may increase the risk of alcohol use. Although these studies contribute to the literature on the association between interpersonal violence experiences and alcohol use, only those conducted by Kilpatrick et al. (2000, 2003) were based on a national sample of adolescents that can be generalized to the U.S. national population as a whole.

\section{CURRENT STUDY}

The current study builds on the available literature on interpersonal violence, traumatic experiences, and alcohol use by studying the experiences of interpersonal physical or sexual violence in a general population sample of 4,564 adolescents who were recruited through a randomized school-based survey of high school students in Florida. Based on previous studies among adolescents, we hypothesized that the likelihood of alcohol use and binge drinking in the past 30 days would be higher among high school students who had been involved in interpersonal violence (physical or sexual assault) than among those who had not been involved in these experiences.

\section{METHOD}

\section{Participants, Measures, and Study Description}

Data for the current study are from the 2005 Florida Youth Risk Behavior Survey (YRBS), which is coordinated nationally every two years by the Centers for Disease Control and Prevention (CDC). Data were derived from a randomized sample of high school students. The sampling methodology of the 2005 Florida YRBS was a two-stage cluster design consisting of schools and students. First, a random sample of schools was selected for participation in the survey. Second, within each selected school, a random sample of classrooms was selected and all students within selected classes were asked to participate in the survey. A total of 4,564 students in 75 public high schools completed the survey. The overall response rate was $66 \%$ (produced by the schools' response rate multiplied by the students' response rate). (For more information on the methodology, see Centers for Disease Control and Prevention [CDC], 2004, 2005). Students completed the YRBS selfadministered questionnaire during one class period (50 minutes). The survey was voluntary and anonymous, and no linking information was collected. The procedures were designed to ensure student privacy. A standard passive consent procedure was used by the school administration. Students were given a consent notification and were asked to give it to their parents. It was then up to the parents to notify the school if they did not want their children to participate in the survey. Students were told that they could skip any question that they were not comfortable answering. Additionally, the written instructions on the front of the survey assured students that participation in the survey was voluntary and their answers would be anonymous.

Participants in the survey were asked to report on two types of experience with interpersonal violence, each in a different time frame: (1) "During the past 12 months, how many times were you in a physical fight?" (one-year time frame); and (2) "Have you ever been physically forced to have sexual intercourse when you did not want to?" 
(lifetime time frame). For each type of violence, participants were categorized as not having experienced it or as having experienced it one time or more. Alcohol use was assessed by the use of alcohol during the past 30 days. Binge drinking was assessed as having five or more drinks in a row (within a couple of hours) during the past 30 days. Alcohol use and binge drinking were categorized as no drinking, one to two days, and three days or more in the past 30 days.

\section{Statistical Analysis}

To determine associations between interpersonal violence experience and alcohol use and binge drinking, our analysis plan was to use a data set based on a large sample of adolescents not localized to a small geographic area, because adolescent behavior could be unique to a specific area. Sample size weighting was done using the YRBS weighting methods. Demographic and school-based characteristics (gender, ethnicity, and school) were used during multilevel sampling, resulting in a sample representative for the state of Florida. First, bivariate relationship was used only for descriptive purposes for the key variables of interest, including the two types of interpersonal violence experience: alcohol use during the past 30 days, and binge drinking during the past 30 days. Second, multivariable multinomial weighted logistic models using the survey logistic procedure in SAS Version 9.2 statistical software were created to determine the association between the interpersonal violence experiences and alcohol use and binge drinking in the past 30 days. The categories used in the multinomial for both dependent variables were " 0 days," "1 to 2 days," and " 3 days or more." The "0 days" variable served as a reference for the other two categories. The models were adjusted for participants' demographic characteristics (gender, ethnicity, and grade) that were available and were found as potential confounders in extant literature (Giaconia et al., 2000; Kilpatrick et al., 2000). The technique of forcing the demographic characteristics into the model ensures that the variance explained by the variable of interest (for example, alcohol use) could not have been due to demographic variables (for example, age or gender). Forcing the demographic characteristics into the model to account for the variable they exhibit in the data does not allow that variability to be part of the variability explained by the variable of interest.
Using an adjusted generalization of the coefficient of determination, $R^{2}$, we determined that both models explained a significant amount of variability in the data. The $p$ values for both models were $<.0001$. The difference between the $-2 \log$ likelihoods of the model with only the demographics compared to the model with the variables of interest was highly significant, with $p$ values $<.0001$. The reference group for gender was female and for ethnicity was African American.

\section{RESULTS}

As shown in Tables 1 and 2, 60\% of students reported no alcohol use. However, 26\% of the male and $32 \%$ of the female students reported drinking alcohol on one to two days in the past 30 days, whereas $12 \%$ of the male students and $9 \%$ of the female students reported drinking on three or more days in the past 30 days. Sorted by ethnicity, $33 \%$ of the Hispanic students reported drinking alcohol on one to two days, whereas $16 \%$ of the ethnic groups labeled "others" (American Indian/ Alaska Natives, Asian, Native Hawaiian or other Pacific Islander) reported drinking on three or more days in the past 30 days. The higher the grade, the higher the consumption of alcohol in the categories of one to two days $34 \%$ of the 12 th-graders) and three or more days $(15 \%$ of the 12th-graders).

Most of the students did not report binge drinking (77\%) (see Table 2). Almost the same percentage of male and female students reported binge drinking one to two days $(12 \%$ and $13 \%$, respectively), whereas $10 \%$ of the male students and $7 \%$ of the female students reported binge drinking three or more days in the past 30 days. Sorting by ethnicity, we found that almost the same percentage of Hispanic and non-Hispanic white students reported binge drinking one to two days (14\% and $15 \%$, respectively). Binge drinking three or more days in the past 30 days was reported most frequently by the "others" category (14\%) and by the non-Hispanic white students (12\%). The higher the grade, the more binge drinking in the past 30 days in the categories of one to two days (18\% of the 12 th-graders) and three or more days $(12 \%$ of the 12th-graders).

Results regarding the statistical relations among the independent variables revealed that more male than female students were involved in physical fighting $(p<.001)$, and more female than male 
Table 1: Demographic Characteristics of the Sample of Alcohol Use in Past 30 days

At Least One Drink During the Past 30 days

\begin{tabular}{|c|c|c|c|c|c|c|}
\hline \multirow[b]{3}{*}{ Category } & \multicolumn{6}{|c|}{ At Least Une Drink During the past so adys } \\
\hline & \multicolumn{2}{|c|}{0 Days } & \multicolumn{2}{|c|}{ 1to 2 Days } & \multicolumn{2}{|c|}{3 Days or More } \\
\hline & $\underset{n}{\text { Sample }}$ & $\begin{array}{c}\text { Weighted } \\
\%\end{array}$ & $\underset{n}{\text { Sample }}$ & $\underset{\%}{\text { Weighted }}$ & $\underset{n}{\text { Sample }}$ & $\begin{array}{c}\text { Weighted } \\
\%\end{array}$ \\
\hline \multicolumn{7}{|l|}{ Gender } \\
\hline Female & 1,361 & 58.8 & 747 & 32.3 & 207 & 8.9 \\
\hline Male & 1,218 & 61.7 & 527 & 26.5 & 237 & 11.8 \\
\hline \multicolumn{7}{|l|}{ Ethnicity } \\
\hline Non-Hispanic White & 1,103 & 54.9 & 628 & 31.9 & 260 & 13.2 \\
\hline Hispanic & 670 & 58.2 & 385 & 33.1 & 99 & 8.7 \\
\hline African American & 629 & 74.1 & 190 & 20.8 & 44 & 5.1 \\
\hline Others & 166 & 59.9 & 68 & 24.0 & 44 & 16.1 \\
\hline \multicolumn{7}{|l|}{ Grade } \\
\hline 9 & 911 & 69.0 & 328 & 23.6 & 108 & 7.4 \\
\hline 10 & 772 & 60.3 & 383 & 30.3 & 115 & 9.4 \\
\hline 11 & 531 & 56.2 & 305 & 32.0 & 111 & 11.8 \\
\hline 12 & 349 & 50.7 & 251 & 34.4 & 107 & 14.9 \\
\hline \multicolumn{7}{|c|}{ Physical fighting in past 12 months } \\
\hline No & 2,036 & 67.7 & 801 & 26.4 & 174 & 5.9 \\
\hline One or more & 527 & 42.9 & 457 & 36.3 & 262 & 20.8 \\
\hline \multicolumn{7}{|c|}{ Ever physically forced to have sex } \\
\hline No & 2,458 & 62.2 & 1,155 & 29.1 & 344 & 8.7 \\
\hline Yes & 123 & 38.4 & 119 & 32.6 & 99 & 29.0 \\
\hline Alcohol use & 2579 & 60.2 & 1274 & 29.4 & 444 & 10.4 \\
\hline
\end{tabular}

Table 2: Demographic Characteristics of the Sample of Binge Drinking in the Past 30 Days

\begin{tabular}{|c|c|c|c|c|c|c|}
\hline \multirow[b]{3}{*}{ Category } & \multicolumn{6}{|c|}{ 5+ Drinks in a Row During the Past 30 Days } \\
\hline & \multicolumn{2}{|c|}{ O Days } & \multicolumn{2}{|c|}{1 to 2 Days } & \multicolumn{2}{|c|}{3 Days or More } \\
\hline & $\begin{array}{c}\text { Sample } \\
n\end{array}$ & $\underset{\%}{\text { Weighted }}$ & $\underset{n}{\text { Sample }}$ & $\underset{\%}{\text { Weighted }}$ & $\begin{array}{c}\text { Sample } \\
n\end{array}$ & $\begin{array}{c}\text { Weighted } \\
\%\end{array}$ \\
\hline \multicolumn{7}{|l|}{ Gender } \\
\hline Female & 1,892 & 79.8 & 300 & 12.8 & 169 & 7.4 \\
\hline Male & 1,596 & 77.5 & 250 & 12.4 & 207 & 10.1 \\
\hline \multicolumn{7}{|l|}{ Ethnicity } \\
\hline Non-Hispanic White & 1,502 & 73.2 & 293 & 14.7 & 237 & 12.1 \\
\hline Hispanic & 953 & 80.2 & 166 & 14.0 & 68 & 5.8 \\
\hline African American & 805 & 90.0 & 58 & 6.6 & 31 & 3.4 \\
\hline Others & 218 & 73.7 & 32 & 12.3 & 41 & 14.0 \\
\hline \multicolumn{7}{|l|}{ Grade } \\
\hline 9 & 1,172 & 84.3 & 133 & 9.3 & 91 & 6.4 \\
\hline 10 & 1,048 & 79.5 & 155 & 12.6 & 98 & 7.9 \\
\hline 11 & 748 & 77.1 & 127 & 13.0 & 94 & 9.9 \\
\hline 12 & 500 & 70.1 & 132 & 17.6 & 89 & 12.3 \\
\hline \multicolumn{7}{|c|}{ Physical fighting in past 12 months } \\
\hline No & 2,624 & 85.1 & 306 & 9.9 & 148 & 5.0 \\
\hline One or more & 836 & 63.7 & 232 & 18.7 & 221 & 17.6 \\
\hline \multicolumn{7}{|c|}{ Ever physically forced to have sex } \\
\hline No & 3,294 & 80.5 & 483 & 12.2 & 285 & 7.3 \\
\hline Yes & 200 & 58.2 & 68 & 17.3 & 88 & 24.5 \\
\hline Binge drinking & 3,488 & 78.7 & 550 & 12.6 & 376 & 8.7 \\
\hline
\end{tabular}


students reported being physically forced to have $\operatorname{sex}(p<.001)$. Forty-seven percent of non-Hispanic white students reported experience with physical fighting, and the same percentage reported being physically forced to have sex $(p<.001)$ compared with $27 \%$ of African American students who reported experience with physical fighting and 31\% who reported being physically forced to have sex $(p<.001)$ (results not shown in tabular form).

\section{Prevalence}

Thirty percent of the students reported being involved one time or more in physical fights in the past year, and $8 \%$ reported being physically forced to have sexual intercourse in their lifetime. Twenty-nine percent of high school students reported using alcohol one or two days in the past 30 days. Thirteen percent of high school students reported binge drinking one or two days in the past 30 days.

Of the students who were involved in fighting in the past year, $36 \%$ reported drinking alcohol on one to two days, while $21 \%$ reported drinking on three days or more in the past 30 days. Of the students who were forced to have sex, 33\% reported drinking alcohol on one to two days, while $29 \%$ reported drinking on three days or more in the past 30 days (see Table 1$)$.
Of the students who were involved in fighting in the past year, $19 \%$ reported binge drinking one to two days, while $18 \%$ reported binge drinking three or more days in the past 30 days. Of the students who were forced to have sex, $17 \%$ reported binge drinking one to two days, while $25 \%$ reported binge drinking three or more days in the past 30 days (see Table 2).

\section{Risk Factors}

The multivariable weighted logistic models for alcohol use and binge drinking in high school students and their association with interpersonal violence experiences are displayed in Tables 3 and 4. After adjusting for gender, ethnicity, and grade, we found that students involved in physical fights had three times greater odds of having used alcohol on one to two days in the past 30 days than students who were not involved in physical fights, and seven times greater odds of having used alcohol on three or more days in the past 30 days than students who were not involved in physical fights $(p<.001)$. Similarly, students who were physically forced to have sexual intercourse had two times greater odds of having used alcohol on one to two days in the past 30 days, and five times greater odds of having used alcohol on three or more days in the past 30 days than students who did not have this experience

\section{Table 3: Multivariable Weighted Logistic Model for Alcohol Use in High School Students and Its Association with Interpersonal Violence Experience}

\begin{tabular}{|c|c|c|}
\hline Category & $\begin{array}{l}1 \text { to } 2 \text { Days vs. } 0 \text { Days Adjusted } \\
\text { OR }(95 \% \mathrm{Cl})\end{array}$ & $\begin{array}{l}3 \text { Days or More vs. O Days } \\
\text { Adjusted OR }(95 \% \mathrm{Cl})\end{array}$ \\
\hline \multicolumn{3}{|l|}{ Gender + } \\
\hline (Female) & 1.00 & 1.00 \\
\hline Male & $0.70(.60,0.83)$ & $1.08(.86,1.36)$ \\
\hline \multicolumn{3}{|l|}{ Ethnicity + } \\
\hline (African American) & 1.00 & 1.00 \\
\hline Non-Hispanic white & $2.37(1.80,3.12)^{* *}$ & $5.71(4.08,7.98)^{* *}$ \\
\hline Hispanic & $2.28(1.77,2.93)^{*}$ & $3.30(2.35,4.60)^{* *}$ \\
\hline Other & $1.69(1.15,2.48)^{* *}$ & $5.41(3.20,9.17)^{* *}$ \\
\hline \multicolumn{3}{|l|}{ Grade + } \\
\hline (9) & 1.00 & 1.00 \\
\hline 10 & $1.59(1.25,2.03)^{* *}$ & $1.75(1.24,2.46)^{* *}$ \\
\hline 11 & $1.83(1.40,2.39)^{* *}$ & $2.52(1.78,3.56)^{* *}$ \\
\hline 12 & $2.36(1.80,3.10)^{* *}$ & $4.18(2.78,6.28)^{* *}$ \\
\hline $\begin{array}{l}\text { Involved in physical fighting in the past } 12 \text { months } \\
\text { (none/ } 1 \text { or more times) }\end{array}$ & $2.78(2.23,3.45)^{* *}$ & $6.82(4.93,9.43)^{* *}$ \\
\hline Physically forced to have sexual intercourse (yes/no) & $1.71(1.27,2.31)^{* *}$ & $5.10(3.52,7.40)^{* *}$ \\
\hline
\end{tabular}

Notes: $N=4,143$. Model fit (Akaike Information Criterion [AIC] model with covariates minus model with intercept only) $=120,459$ with 18 degrees of freedom. $\mathrm{Cl}=$ confidence interval; $O R=$ odds ratio; $+=$ forced into the model. Reference groups are in parentheses. ${ }^{*} p<.01 .{ }^{* *} p<.001$. 


\begin{tabular}{lcc}
$\begin{array}{l}\text { Table 4: Multivariable Weighted Logistic Model for Binge Drinking in High School Students } \\
\text { and Its Association with Interpersonal Violence Experience }\end{array}$ & $\begin{array}{c}\text { 3 days or more vs. O days } \\
\text { Adjusted OR (95\% Cl) }\end{array}$ \\
$\begin{array}{lcc}\mathbf{1} \text { to } \mathbf{2} \text { days vs. O days } \\
\text { Adjusted OR (95\% Cl) }\end{array}$ & 1.00 \\
Categories & 1.00 & $1.22(.87,1.73)$ \\
\hline $\begin{array}{l}\text { Gender + } \\
\text { (Female) }\end{array}$ & $0.90(.74,1.10)$ & 1.00 \\
Male & & $7.76(4.72,12.76)^{* *}$ \\
Ethnicity + & 1.00 & $3.03(1.78,5.14)^{* *}$ \\
(African American) & $3.29(2.32,4.66)^{* *}$ & $7.83(4.39,13.96)^{* *}$ \\
Non-Hispanic white & $2.76(1.98,3.84)^{* *}$ & 1.00 \\
Hispanic & $2.20(1.37,3.54)^{* *}$ & $1.67(1.20,2.34)^{*}$ \\
Other & & $2.20(1.51,3.18)^{* *}$ \\
Grade + & 1.00 & $3.51(2.30,5.39)^{* *}$ \\
(9) & $1.55(1.12,2.16)^{*}$ & \\
10 & $1.77(1.31,2.38)^{* *}$ & $5.54(4.25,7.21)^{* *}$
\end{tabular}

Note: $N=4,143$. Model fit (Akaike Information Criterion [AIC] model with covariates minus model with intercept only) =107,156 with 18 degrees of freedom. Cl = confidence interval; $O R=$ odds ratio; $+=$ forced into the model. Reference groups are in parentheses. ${ }^{*} p<.01 .{ }^{* *} p<.001$.

$(p<.001)$. Gender interaction was not significant for being involved in physical fights or being forced to have sexual intercourse (results not shown in tabular form).

After adjusting for gender, ethnicity, and grade, we found that students involved in physical fights had three times greater odds of binge drinking on one to two days in the past 30 days than students who were not involved in physical fights and five times greater odds of binge drinking on three or more days in the past 30 days than students who were not involved in physical fights $(p<.001)$. Similarly, students who were physically forced to have sexual intercourse had almost two times greater odds of binge drinking on one to two days in the past 30 days and four times greater odds of binge drinking on three or more days in the past 30 days than students who did not have this experience $(p<.001)$. Gender interaction was not significant for being involved in physical fights or being forced to have sexual intercourse (results not shown in tabular form).

\section{DISCUSSION}

Using a school-based sample of 4,564 high school adolescents, we found a high prevalence of students who had experienced interpersonal violence through physical fights $(30 \%)$ or being physically forced to have sexual intercourse (8\%). As hypothesized, students who were involved in physical fights or were physically forced to have sexual intercourse were significantly more likely to have consumed alcohol on either one to two days or three or more days in the past 30 days than students who were not involved in these types of interpersonal violence.

\section{Interpersonal Violence and Alcohol Use}

High prevalence of interpersonal violence and traumatic experiences among adolescents has been documented before, but the overall prevalence has been inconsistent and varies by the type of violence experience and by the characteristics of the sample (Kilpatrick et al., 2003; Silverman et al., 2008). For example, Boney-McCoy and Finkelhor (1995) found a $10.5 \%$ prevalence of sexual assault in adolescents ages 10 to 16 years in a national sample, whereas Hamburger et al. (2008) found 8.9\% prevalence in adolescents in a high-risk community. The high prevalence of high school students who reported physical or sexual violence experiences in the current study strengthens the results of the few previous studies that made comparable observations among adolescents (for example, 
Boney-McCoy \& Finkelhor, 1996; Giaconia et al., 2000; Kilpatrick et al., 2003; Thompson, Sims, Kingree, \& Windle, 2008). Furthermore, the current study used data from the 2005 Florida YRBS, with a solid response rate of $66 \%$ and a fairly diverse sample of ethnicity. Although numerous studies have documented an association between violence experiences and alcohol use among adults, limited research has investigated the association between interpersonal violence experiences and alcohol use among adolescents. In the general population of adolescents, studies have examined interpersonal violence experiences or childhood maltreatment and various mental health outcomes (for example, Boney-McCoy \& Finkelhor, 1995, 1996; Margolin et al., 2009; Stein et al., 2003; Voisin, 2007). However, limited research exists on the link between interpersonal violence experiences and alcohol use outcomes in this population (Giaconia et al., 2000; Hamburger et al., 2008; Kilpatrick et al., 2000, 2003). The current study shows that students who were involved in interpersonal violence experiences were significantly more likely to have consumed alcohol in the past 30 days. Research has suggested that violence plays a role in adolescent and adult substance abuse (Kilpatrick et al., 2000). A potential mechanism to explain the risk factors of interpersonal violence experiences on alcohol use among adolescents can be found in the stress and coping theory developed by Lazarus and Folkman (1984). Adolescents may experience violence as a stressful experience and use alcohol to self-medicate. Substance use may represent a maladaptive strategy to cope with the stress of interpersonal violence (Kilpatrick et al., 2000). According to the self-medication hypothesis, adolescents use substances in an attempt to relieve the memories and other symptoms of a stressful experience (Chilcoat \& Breslau, 1998). Moreover, Hamburger et al. (2008) found that even a "passive experience" such as witnessing violence was associated with initiation of alcohol use in early adolescence. However, there might be alternative explanations for the link between involvement in interpersonal violence and alcohol use: (a) alcohol use may increase the risk of involvement in interpersonal violence; (b) involvement in interpersonal violence and alcohol use can share common causes; or (c) involvement in interpersonal violence and alcohol use may be linked coincidentally.

\section{Limitations}

The current study has several limitations. First, results based on cross-sectional data cannot establish a causal relationship between interpersonal violence experiences and alcohol use among adolescents. It is possible that alcohol use may predispose adolescents to participate in violence. However, our measures of lifetime and past-year experience of interpersonal violence and pastmonth alcohol use provide some reassurance that the observed relation operates in the hypothesized direction. Furthermore, the impact of alcohol use on the vulnerability to future violence or any potentially traumatic experience cannot be determined (Chilcoat \& Breslau, 1998). Second, this study relied on self-reporting by students, and the extent of underreporting or overreporting of behaviors cannot be determined. However, most surveys of adolescents about substance use rely on self-report measurements, and the results have been shown to be valid and reliable (Barnea, Rahav, \& Teichman, 1987). Third, this study is based on data from an existing survey with specific variables (some potentially confounding factors that might be involved, such as family violence and mental illness, were not investigated in this study), and there are differences in time span between the measurement of involvement in physical fighting in the past year, the measurement of being forced to have sexual intercourse during one's lifetime, and the measurement of alcohol use in the past 30 days. Taking this limitation into consideration, this study is an exploratory study. Finally, the current study focused on adolescents who attend public schools and therefore may not represent the general population of adolescents in private schools or not attending any school system (a population that might be at high risk for interpersonal violence experiences and alcohol use).

Despite these limitations, this study contributes to the literature by documenting the high prevalence of physical or sexual violence and the risk factor of alcohol use in a large and diverse sample of adolescents in the 9th to 12th grade. As a survey of a representative sample in Florida, the study investigated interpersonal violence experiences and alcohol use among the general population of adolescents and not among adolescents in clinical settings of alcohol or drug treatment where adolescents with traumatic histories may be overrepresented. Finally, this single study investigated different types 
of interpersonal violence experiences (physical and sexual).

\section{Implications for Social Work Research and Practice}

The current study has implications for social work research and practice. It reinforces the need to include questions about interpersonal violence in surveys about alcohol use among adolescents as part of screening for risk factors among high school students and patients entering social work intervention. The violence experience by itself is not necessarily the direct cause (or perhaps result) of alcohol use, but other factors such as the associated trauma experience due to interpersonal violence and the child's personality, genetic makeup, and family or environmental relationships may play a role. Investigating these topics further in research and practice will help us to better understand the mechanisms of how interpersonal violence experiences are associated with alcohol use. Given the social work profession's involvement with family, school, and community violence, further research in this field is needed to understand violence and its connection with alcohol use among adolescents.

Results of the study support the importance of clinical prevention programs in high schools focusing not only on alcohol use or on the interpersonal violence of physical fights and forced sexual intercourse, but also on a combination of these factors (Roe-Sepowitz \& Krysik, 2008). Adolescents who have faced interpersonal violence experiences may be at a high risk for alcohol use and in need of clinical intervention, even if they do not currently show any external or internal behavior problems such as irritation, depression, or low academic performance (Kilpatrick et al., 2003; Silverman et al., 2008). Clearly, children at high risk need to be included in prevention and counseling programs in schools and in community settings.

\section{Recommendations for Future Research}

To address the limitations and extend this study's findings, there are several directions for future research. A strong association was found between ethnicity and alcohol use in the study. After adjusting for ethnicity, we found that the association between interpersonal violence and alcohol use was still strong. More research is needed to investigate this association and to develop violence prevention and intervention strategies to build evidence-based knowledge for practice (Proctor, 2002). Furthermore, the results suggest that the early evaluation of interpersonal violence experiences may be important as part of alcohol use prevention programs among adolescents. However, comprehensive measures of violence are needed to obtain a complete picture of the prevalence of interpersonal violence among adolescents and its relation to alcohol use.

This study supports the notion that there is a significant relation between interpersonal violence experiences and alcohol use in a high school population. Students who were involved in interpersonal violence experiences of physical fights or were physically forced to have sexual intercourse were significantly more likely to have consumed alcohol than students who were not involved in these types of interpersonal violence. Findings suggest that early evaluation of interpersonal violence experiences may be important as part of alcohol use prevention programs among adolescents. The study supports the importance of clinical prevention programs in high schools focusing on a combination of alcohol use and interpersonal violence of physical fights and forced sexual intercourse. SWW

\section{REFERENCES}

Aisenberg, E., \& Herrenkohl, T. (2008). Community violence in context: Risk and resilience in children and families. Journal of Interpersonal Violence, 23, 296-315.

Barnea, Z., Rahav, G., \& Teichman, M. (1987). The reliability and consistency of self-reports on substance use in a longitudinal study. British Journal of Addiction, 82, 891-898.

Boney-McCoy, S., \& Finkelhor, D. (1995). Psychosocial sequelae of violent victimization in a national youth sample. Journal of Consulting and Clinical Psychology, 63, 726-736.

Boney-McCoy, S., \& Finkelhor, D. (1996). Is youth victimization related to trauma symptoms and depression after controlling for prior symptoms and family relationships? A longitudinal, prospective study. Journal of Consulting and Clinical Psychology, 64, 1406-1416.

Breslau, N., Davis, G. L., \& Schultz, L. R. (2003). Posttraumatic stress disorder and the incidence of nicotine, alcohol, and other drug disorders in persons who have experienced trauma. Archives of General Psychiatry, 60, 289-294.

Centers for Disease Control and Prevention. (2004, September). Methodology of the youth risk behavior surveillance system. Morbidity and Mortality Weekly Report, 53, RR-12. Retrieved from http://www.cdc. gov/mmwr/PDF/rr/rr5312.pdf

Centers for Disease Control and Prevention. (2005). Youth risk behavior surveillance system (YRBSS). Retrieved from http://www.cdc.gov/HealthyYouth/yrbs/index.htm

Chilcoat, H. D., \& Breslau, N. (1998). Investigations of causal pathways between PTSD and drug use disorders. Addictive Behaviors, 23, 827-840. 
Deykin, E. Y., \& Buka, S. L. (1997). Prevalence and risk factors for posttraumatic stress disorder among chemically dependent adolescents. American Journal of Psychiatry, 154, 752-757.

Evans, A. S., Spirito, A., Celio, M., Dyl, J., \& Hunt, J. (2007). The relation of substance use to trauma and conduct disorder in adolescent psychiatric population. Journal of Child and Adolescents Substance Abuse, 17, 29-49.

Giaconia, R. M., Reinherz, H. Z., Hauf, A. C., Paradis, A. D., Wasserman, M. S., \& Langhammer, D. M. (2000). Comorbidity of substance use and posttraumatic stress disorders in a community sample of adolescents. American Journal of Orthopsychiatry, 70, 253-262.

Goodwin, R. D., \& Stein, M. B. (2004). Association between childhood trauma and physical disorders among adults in the United States. Psychological Medicine, 34, 509-520.

Hamburger, M. E., Leeb, R. T., \& Swahn, M. H. (2008). Childhood maltreatment and early alcohol use among high-risk adolescents. Journal of Studies on Alcohol and Drugs, 69, 291-295.

Hawke, J. M., Ford, J. D., \& Kaminer, Y. (2005, June 1823). Trauma among youths in AOSUD treatment. Presentation at the College on Problems of Drug Dependence, Orlando, FL.

Hedtke, K. A., Ruggiero, K. J., Fitzgerald, M. M., Zinzow, H. M., Saunders, B. E., Resnick, H. S., et al. (2008). A longitudinal investigation of interpersonal violence in relation to mental health and substance use. Journal of Consulting and Clinical Psychology, 76, 633-646.

Kilpatrick, D. G., Acierno, R., Resnick, H. S., Saunders, B. E., \& Best, C. L. (1997). Two-year longitudinal analysis of the relationships between violent assault and substance use in women. Journal of Consulting and Clinical Psychology, 65, 834-847.

Kilpatrick, D. G., Acierno, R., Saunders, B., Resnick, H. S., Best, C. L., \& Schnurr, P. P. (2000). Risk factors for adolescent substance abuse and dependence: Data from a national sample. Journal of Consulting and Clinical Psychology, 68, 19-30.

Kilpatrick, D. G., Ruggiero, K. J., Acierno, R., Saunders, B. E., Resnick, H. S., \& Best, C. L. (2003). Violence and risk of PTSD, major depression, substance abuse/ dependence, and comorbidity: Results from the National Survey of Adolescents. Journal of Consulting and Clinical Psychology, 71, 692-700.

Langeland, W., \& Hartgers, C. (1998). Child sexual and physical abuse and alcoholism: A review. Journal of Studies on Alcohol and Drugs, 59, 336-348.

Lazarus, R. S., \& Folkman, S. (1984). Stress, appraisal, and coping. New York: Springer.

Lynch, M. (2003). Consequences of children's exposure to community violence. Clinical Child and Family Psychology Review, 6, 265-274.

Margolin, G., Vickerman, K. A., Ramos, M. C., Serrano, S. D., Gordis, E. B., Iturralde, E., et al. (2009). Youth exposed to violence: Stability, co-occurrence, and context. Clinical Child and Family Psychology Review, 12, 39-54.

Monitoring the Future survey [Table 3: Trends in 30-day prevalence of use of various drugs in grades 8,10 , and 12]. (2010). Retrieved from http://monitoringthefuture. org/data/10data/pr10t3.pdf

Morris, S. L., \& Wagner, E. F. (2007). Adolescent substance use: Developmental considerations [Florida Certification Board/Southern Coast ATTC Monograph Series No. 1]. Retrieved from http://www.nattc.org/ regcenters/productDocs/14/Adolescent_ Monograph_1.pdf
Proctor, E. K. (2002). Social work, school violence, mental health, and drug abuse: A call for evidence-based practices [Editorial]. Social Work Research, 26, 67-69.

Reijneveld, S. A., Crone, M. R., Verhulst, F. C., \& Verloove-Vanhorick, S. P. (2003). The effect of a severe disaster on the mental health of adolescents: A controlled study. Lancet, 362, 691-696.

Roe-Sepowitz, D., \& Krysik, J. (2008). Examining the sexual offenses of female juveniles: The relevance of childhood maltreatment. American Journal of Orthopsychiatry, 78, 405-412.

Silverman, W. K., Ortiz, C. D., Viswesvaran, C., Burns, B. J., Kolko, D. J., Putnam, F. W., et al. (2008). Evidence-based psychosocial treatments for children and adolescents exposed to traumatic events. Journal of Clinical Child \& Adolescent Psychology, 37, 156-183.

Spatz Widon, C., Raskin White, H., Czaja, S. J., \& Marmorstein, N. R. (2007). Long-term effects of child abuse and neglect on alcohol use and excessive drinking in middle adulthood. Journal of Studies on Alcohol and Drugs, 68, 317-326.

Stein, B. D., Jaycox, L. H., Kataoka, S., Rhodes, H. J., \& Vestal, K. D. (2003). Prevalence of child and adolescent exposure to community violence. Clinical Child and Family Psychology Review, 6, 247-264.

Thompson, M. P., Sims, L., Kingree, J. B., \& Windle, M. (2008). Longitudinal associations between problem alcohol use and violent victimization in a national sample of adolescents. Journal of Adolescents Health, 42, 21-27.

Vlahov, D., Galea, S., Resnick, H., Ahern, J., Boscarino, J. A., Bucuvalas, M., et al. (2002). Increased use of cigarettes, alcohol, and marijuana among Manhattan, New York, residents after the September 11th terrorist attacks. American Journal of Epidemiology, 155, 988-996.

Voisin, D. R. (2007). The effects of family and community violence exposure among youth: Recommendations for practice and policy. Journal of Social Work Education, 43, 51-66.

Zatzick, D. F., Grossman, D. C., Russo, J., Pynoos, R., Berliner, L., Jurkovich, G., et al. (2006). Predicting posttraumatic stress symptoms longitudinally in a representative sample of hospitalized injured adolescents. Journal of the American Academy of Child Adolescents Psychiatry, 45, 1188-1195.

Neta Peleg-Oren, PhD, MSW, is assistant professor (voluntary), Gabriel A. Cardenas, $\mathbf{M P H}$, is lead analyst, Mary Comerford, $\mathbf{M S P H}$, is senior research associate, Department of Epidemiology and public health, University of Miami, Miller School of Medicine, Miami. Sandro Galea, MD, MPH, DrPH, is chair, Department of Epidemiology, Mailman School of Public Health, and professor of epidemiology, Anna Cheskis Gelman and Murray Charles Gelman, Columbia University, New York. Send correspondence to Neta Peleg-Oren; e-mail: npelegoren@med.miami.edu.

Original manuscript received July 6, 2010 Final revision received August 2, 2011 Accepted February 28, 2012 